\title{
Laboratory Safety Awareness Among General Physics Undergraduate Students
}

\author{
Celina O. Ponferrada \\ Department of Physics \\ College of Science and \\ Mathematics \\ University of Science and \\ Technology of Southern Philippines \\ Cagayan de Oro, 9000 Philippines \\ celinaponferrada25@gmail.com

\section{Geraldine D Labial \\ Department of Physics \\ College of Science and \\ Mathematics \\ University of Science and} \\ Technology of Southern Philippines \\ Cagayan de Oro, 9000 Philippines \\ Cagayan de Oro, Philippines
}

\author{
Earl John L. Cabigon \\ Department of Physics \\ College of Science and \\ Mathematics \\ University of Science and \\ Technology of Southern Philippines \\ Cagayan de Oro, 9000 Philippines \\ earljohn_cabigon@yahoo.com
Don Christian L. Buadlart
Department of Physics
College of Science and Mathematics
University of Science and
Cagayan de Oro, 9000 Philippines
donbuadlart@gmail.com \\ Technology of Southern Philippines
}

\author{
Jesryl G. Daque \\ Department of Physics \\ College of Science and Mathematics \\ University of Science and \\ Technology of Southern Philippines \\ Cagayan de Oro, 9000 Philippines \\ jesryldaque1@gmail.com
}
Van Ryan Kristopher R. Galarpe Department of Physics/Department of Environmental Science \& Technology College of Science and Mathematics University of Science and
Technology of Southern Philippines Cagayan de Oro, 9000 Philippines vanryangalarpe@gmail.com

\begin{abstract}
Safety awareness in the laboratory is essential to reduce occupational risks. This study was conducted to determine the students' safety awareness in a Physics laboratory. This study determined the student perception towards safety awareness by factors of gender and college from which students are enrolled. A sum of 324 students enrolled in Physics10 (Mechanics and Heat) and Physics11 (Electricity and Magnetism) in the Mindanao University of Science and Technology (MUST) were randomly selected as survey respondents. A modified survey questionnaire was used as research instrument. The results show that the students had positive level of safety awareness and perceived positively on the preventive measures to reduce laboratory risk. Further, regardless of gender students enrolled in Physics 10 were more positively aware towards safety awareness than students enrolled in Physics 11. Similarly, a variation among the students perception towards safety awareness from the College of Engineering and Architecture (CEA) and College of Industrial and Information Technology (CIIT) occurred. Overall, present findings indicate a need to introduce laboratory safety awareness in Physics classes.
\end{abstract}

Keywords-Physics laboratory; safety awareness; preventive measures

\section{INTRODUCTION}

Safety awareness is a critical component in a workplace especially in a laboratory, a facility implementing scientific discipline owing to health hazards exposure [1]. It is therefore essential for safety awareness to be observed considering the occupational hazards are inevitable. Good laboratory practice
(GLP) must similarly be implemented in a science laboratory or in any educational research entity [2-6]. Laboratory malpractice may occur whenever a laboratory working staff or technician fails to oversee the safety, accuracy, and precision of a laboratory work. In return this requires compliance to GLP protocols to ensure safety. The gaps on this area can be associated to less attention on (1) introduction to the laboratory safety rules, (2) presentation of an experiment's specific safety concern, and (3) basic quizzes regarding to the safety rules [7]. In an undergraduate laboratory the students are centered towards handling equipment and activities [3] which may directly expose them to potential risk. To minimize the risk it is essential that students themselves learn some basics about specific risks. However, most studies on GLP awareness are focused on chemical testing education facilities [4-6, 8-10] and no literature was found to be focused on assessing students' awareness in Physics laboratories. The use of electronics and electrical equipment in Physics laboratory presents similar potential occupational risks as much as the use of chemicals. This study was conducted in order to assess the safety awareness of Physics 10 (Mechanics and Heat) and Physics 11 (Electricity and Magnetism) among enrolled students in the former Mindanao University of Science and Technology (MUST). The objectives were to determine the status of preventive measures implemented to reduce laboratory risk, to determine the perception of students towards laboratory safety by gender and by the college the students belong. 


\section{MATERIALS AND METHODS}

\section{A. Framework}

This study was conducted based on a former study on laboratory safety [4]. Further, this was conducted to assess the safety awareness of the former Mindanao University of Science and Technology, now University of Science and Technology of Southern Philippines (USTP) students enrolled in Physics10 and Physics11 from different colleges and programs of the university (see Figure 1). A descriptive method of research was employed. This was done through modified questionnaire. The considered factors were: (1) status of the risks they encounter in the Physics laboratory; (2) the status of preventive measures the students have taken to avoid risk (3) gender of the respondents and (4) the college where the students belong. Figure 1 presents the conceptual framework of the study.

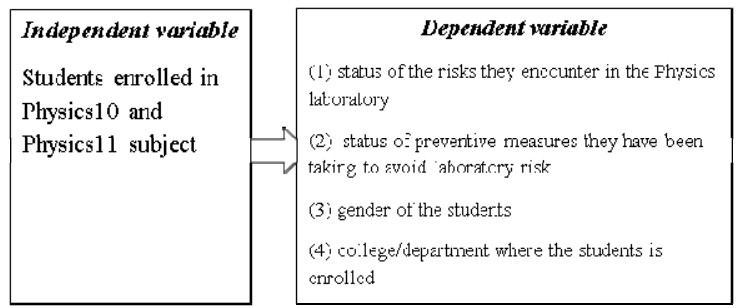

Fig. 1. Framework of the study

\section{B. Respondents of the Study}

The number of participants of the study was taken from the actual number of students on the first semester of 2016-2017. 324 students were randomly selected from a total of 1734 enrolled students in Physics course. The Slovin's formula was used to randomly determine the number of respondents.

\section{Questionnaire}

The questionnaire was anchored from [1] to fit with the objectives of this study. The first section of the questionnaire tried to identify the perceived risk in the Physics laboratory. Given choices were, strongly agree (SA), agree (A), neutral $(\mathrm{N})$, disagree (D), strongly disagree (SD). The second section of the survey questionnaire was categorical on the safety measures taken in the Physics laboratory.

\section{Data Analysis}

All results were presented descriptively using frequency, mean, and percentage. The independent t-test was used to statistically determine if there is a significant difference on the students' level of safety awareness in Physics laboratory by gender and by college they are enrolled.

\section{RESULTS AND DISCUSSIONS}

\section{A. Safety Awareness of Students}

The first parameter of this study determined the awareness of the students towards laboratory safety. All results were presented in the form of mean. Tables I and II present the perception of students towards Physics laboratory safety. Overall, students were aware of the laboratory risks. The positive perception of the students could be reinforced by their Chemistry and other sciences laboratory classes. Present findings suggest a good laboratory awareness and workenvironment sensitivity among tertiary students [11].

TABLE I. UNDERGRADUATE STUDENTS IN PHYSICS 10 PERCEPTION ON LABORATORY SAFETY

\begin{tabular}{|c|c|c|c|c|c|}
\hline \multirow{2}{*}{ Perception statement } & \multicolumn{5}{|c|}{ Physics 10 (Mechanics \& Heat) } \\
\cline { 2 - 6 } & SA & A & N & D & SD \\
\hline $\begin{array}{c}\text { Know that all activities in the } \\
\text { Laboratory have health risk. }\end{array}$ & 330 & 284 & 72 & 2 & 0 \\
\hline Dust is dangerous to health. & 420 & 216 & 63 & 4 & 1 \\
\hline Smoke is dangerous to health. & 680 & 80 & 9 & 0 & 3 \\
\hline $\begin{array}{c}\text { Chemical reactions can result in fire } \\
\text { hazard and poisonous gases. }\end{array}$ & 535 & 192 & 15 & 2 & 1 \\
\hline Burning can result in hazard. & 470 & 224 & 33 & 0 & 1 \\
\hline $\begin{array}{c}\text { Explosions can take place in } \\
\text { laboratory. }\end{array}$ & 475 & 200 & 45 & 2 & 1 \\
\hline $\begin{array}{c}\text { Sudden increase of temperature in } \\
\text { the laboratory is dangerous. }\end{array}$ & 370 & 244 & 69 & 8 & 1 \\
\hline $\begin{array}{c}\text { Loud noise while working with wood } \\
\text { and metal in the laboratory is } \\
\text { dangerous to health. }\end{array}$ & 175 & 172 & 135 & 24 & 7 \\
\hline $\begin{array}{c}\text { Not washing hands with soap after } \\
\text { activity in the laboratory is } \\
\text { dangerous. }\end{array}$ & 470 & 176 & 45 & 6 & 7 \\
\hline $\begin{array}{c}\text { It is important to make sure that the } \\
\text { current is turned off before making } \\
\text { adjustments in the circuit. }\end{array}$ & 560 & 132 & 42 & 4 & 0 \\
\hline $\begin{array}{c}\text { Before turning on an electrical } \\
\text { circuit, the instructor must first be } \\
\text { asked to inspect the circuit. }\end{array}$ & 540 & 148 & 33 & 0 & 3 \\
\hline
\end{tabular}

Legend: strongly agree (SA), agree (A), neutral (N), disagree (D), strongly disagree (SD)

TABLE II. UNDERGRADUATE STUDENTS IN PHYSICS 11 PERCEPTION ON LABORATORY SAFETY

\begin{tabular}{|c|c|c|c|c|c|}
\hline \multirow[t]{2}{*}{ Perception statement } & \multicolumn{5}{|c|}{$\begin{array}{c}\text { Physics } 11 \text { (Electricity \& } \\
\text { Magnetism) }\end{array}$} \\
\hline & SA & $\mathbf{A}$ & $\mathbf{N}$ & D & SD \\
\hline $\begin{array}{l}\text { Know that all activities in the } \\
\text { Laboratory have health risk. }\end{array}$ & 335 & 268 & 69 & 8 & 1 \\
\hline Dust is dangerous to health. & 385 & 248 & 57 & 10 & 1 \\
\hline Smoke is dangerous to health. & 560 & 108 & 30 & 8 & 1 \\
\hline $\begin{array}{l}\text { Chemical reactions can result in fire } \\
\text { hazard and poisonous gases. }\end{array}$ & 505 & 180 & 36 & 8 & 0 \\
\hline Burning can result in hazard. & 490 & 192 & 36 & 6 & 1 \\
\hline $\begin{array}{c}\text { Explosions can take place in } \\
\text { laboratory. }\end{array}$ & 430 & 196 & 36 & 6 & 1 \\
\hline $\begin{array}{l}\text { Sudden increase of temperature in } \\
\text { the laboratory is dangerous. }\end{array}$ & 320 & 270 & 66 & 10 & 5 \\
\hline $\begin{array}{l}\text { Loud noise while working with wood } \\
\text { and metal in the laboratory is } \\
\text { dangerous to health. }\end{array}$ & 225 & 216 & 90 & 58 & 8 \\
\hline $\begin{array}{l}\text { Not washing hands with soap after } \\
\text { activity in the laboratory is } \\
\text { dangerous. }\end{array}$ & 420 & 180 & 63 & 24 & 3 \\
\hline $\begin{array}{l}\text { It is important to make sure that the } \\
\text { current is turned off before making } \\
\text { adjustments in the circuit. }\end{array}$ & 500 & 172 & 33 & 12 & 2 \\
\hline $\begin{array}{l}\text { Before turning on an electrical } \\
\text { circuit, the instructor must first be } \\
\text { asked to inspect the circuit. }\end{array}$ & 460 & 192 & 42 & 10 & 3 \\
\hline
\end{tabular}

Legend: strongly agree (SA), agree (A), neutral (N), disagree (D), strongly disagree (SD) 


\section{B. Students Perceived Preventive Measures}

Students' perception on the preventive measures in the Physics laboratory is shown in Figures 2-5. Perception statements were answered categorically. The use of PPE's was positively responded by students enrolled in both Physics 10 and 11 (see Figure 2). These students were similarly enrolled in Chemistry laboratory classes which reinforced GLP and PPE use. However about $45 \%$ of students in Physics 10 and $37 \%$ in Physics 11 do not use PPE's (see Figure 3). This result can be associated to the lack of laboratory protocols in Physics. Figure 4 showed less perceived response towards noise protection owing to limited experiments involving sound. On the other hand, about $88.27 \%$ and $87.65 \%$ of students enrolled in Physics 10 and $82.09 \%$ and $79.01 \%$ of students enrolled in Physics 11 responded positively towards radiation avoidance or any potential source of heating relevant to Physics laboratory (Figure 5).

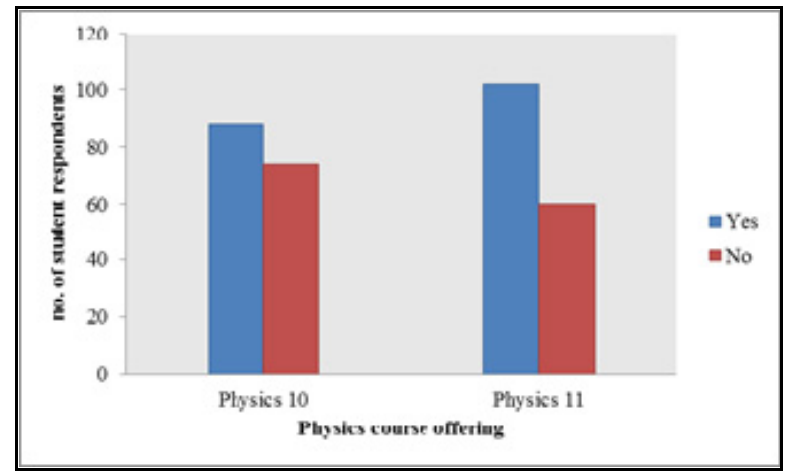

Fig. 2. Students' response on having personal protective equipment (PPE) in the Physics laboratory

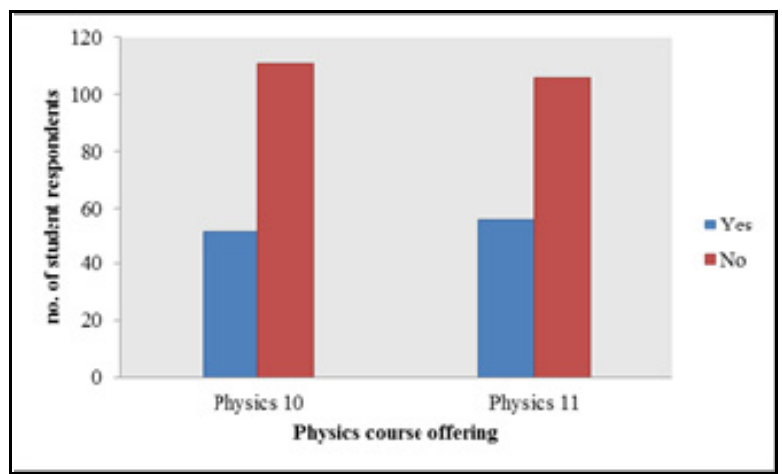

Fig. 3. Students' response on using PPE as ear protection against Physics laboratory noise

\section{Students Perception by Gender}

The third parameter was designed to determine if gender plays a factor towards the level of safety (see Table III). A null hypothesis was established and tested by an independent t-test (level of significance is 0.05 ). Overall, there was a significant difference in the level of awareness between male and female students enrolled in Physics10 $\left(t_{\text {cal }}=2.28>t_{\text {crit }}=1.65\right)$. The students of Physics11 had similar level of safety awareness in the Physics laboratory $\left(\mathrm{t}_{\mathrm{cal}}=1.31<1.65\right)$.

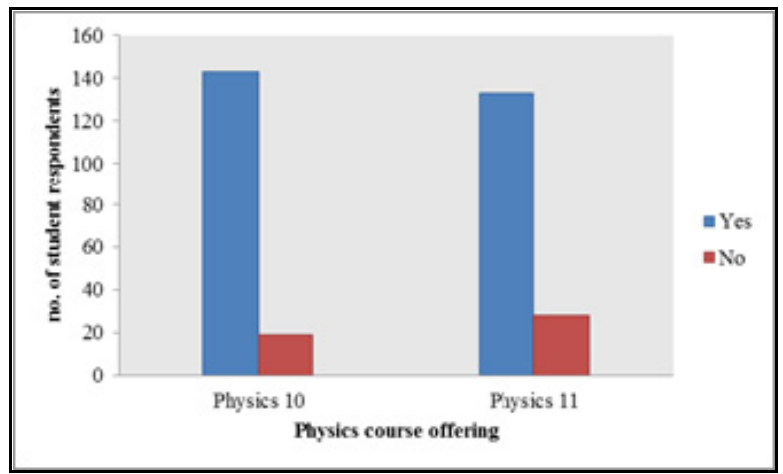

Fig. 4. Students response on avoiding to potential source of experiments involving heating

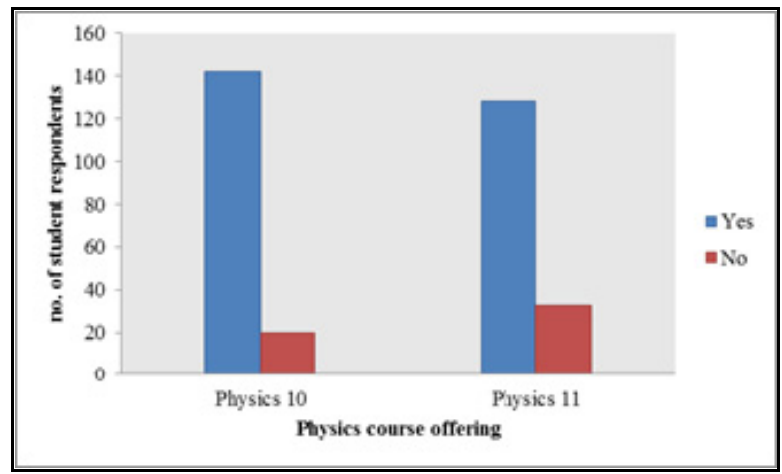

Fig. 5. Students response on avoiding radiation sources in Physics laboratory

TABLE III. T-TABLE ON STUDENTS PERCEPTION ON PHYSICS LABORATORY SAFETY BY GENDER

\begin{tabular}{|c|c|c|c|c|}
\hline \multirow{2}{*}{ Gender } & \multicolumn{2}{|c|}{ Physics10 } & \multicolumn{2}{c|}{ Physics11 } \\
\cline { 2 - 5 } & $\mathbf{t}_{\text {critical }}$ & $\mathbf{t}_{\text {calculated }}$ & $\mathbf{t}_{\text {critical }}$ & $\mathbf{t}_{\text {calculated }}$ \\
\hline Male & 1.65 & 2.28 & 1.65 & 1.31 \\
\hline Female & 1.65 & 2.28 & 1.65 & 1.31 \\
\hline
\end{tabular}

\section{Student Perception by College}

The fourth parameter was designed to determine if the college the students were enrolled can be a factor towards the level of safety awareness among students in Physics courses. A null hypothesis was established and tested by an independent ttest (level of significance is 0.05 ). However, owing to limited students enrolled in Physics only three colleges were considered in the former MUST, namely, (i) College of Industrial and Information Technology (CIIT); (ii) College of Engineering and Architecture (CEA); and (iii) College of Arts and Sciences (CAS). Overall, students from CIIT and CEA in both Physics 10 and Physics 11 showed variation in their level of safety awareness $\left(t_{\text {cal }}>t_{\text {crit }}\right)$. The present findings can be attributed to minimal exposure of CIIT and CEA students to 
natural sciences laboratories unlike CAS students. These laboratories were perceived to reinforced GLP and safety awareness common among CAS students. Nonetheless, the findings can be a basis to develop learning strategies on safety awareness among CIIT and CEA students (see Table IV).

TABLE IV. T-TABLE ON STUDENTS PERCEPTION ON PHYSICS LABORATORY SAFETY BY COLLEGE

\begin{tabular}{|c|c|c|c|c|}
\hline \multirow{2}{*}{ College } & \multicolumn{2}{|c|}{ Physics10 } & \multicolumn{2}{c|}{ Physics11 } \\
\cline { 2 - 5 } & $\mathbf{t}_{\text {critical }}$ & $\mathbf{t}_{\text {calculated }}$ & $\mathbf{t}_{\text {critical }}$ & $\mathbf{t}_{\text {calculated }}$ \\
\hline CIIT & 1.96 & 2.81 & 1.96 & 2.81 \\
\hline CEA & 1.96 & 8.02 & 1.96 & 8.02 \\
\hline CAS & 1.96 & 1.65 & 1.96 & 1.65 \\
\hline
\end{tabular}

$\mathrm{N}=162 ;$ Not significant; $\mathrm{P}>.05$

\section{CONCLUSIONS}

This study investigates the level of students' safety awareness in a Physics laboratory. The study considers factors such as the gender and the college where students are enrolled. A modified survey questionnaire is used as research instrument. Results suggest that students should be more informed towards Physics laboratory safety. Students and faculty evaluation should be incorporated to assess further the safety awareness in Physics laboratory Overall, present findings indicate a need to introduce laboratory safety awareness in Physics classes.

\section{REFERENCES}

[1] A. O. Udoh, "Status of Safety Awareness among Senior Secondary School Science Students in Akwa Ibom State of Nigeria", Academic Journal of Interdisciplinary Studies, Vol. 2, No. 2, pp. 275-279, 2013
[2] B. D. Backus, K. Fivizzani, T. Goodwin, D. Finster, E. Austin, W. Doub, S. D. Wiediger, S. Kinsley, "Laboratory safety culture: Summary of the chemical education research and practice - Safety in chemistry education panel discussion at the 46th Midwest and 39th Great Lakes Joint Regional American Chemical Society Meeting, St. Louis, Missouri, on October 21, 2011", In Journal of Chemical Health and Safety, Vol. 19, No. 4, pp. 20-24, 2012

[3] R. Artdej, "Investigating undergraduate students' scientific understanding of laboratory safety", Procedia-Social and Behavioral Sciences, Vol. 46, pp. 5058-5062, 2012

[4] V. R. K. R Galarpe, N. C. Lamela, R. Alcantara, "Preliminary evaluation of laboratory practices in Cebu Doctors' University, Philippines", Journal of Chemical Health and Safety, Vol. 20, No. 4, pp. 25-30, 2013

[5] M. A. Balkhiour, "Evaluation of the Safety Status in Some University Laboratories", Journal of King Abdulaziz University: Meteorology, Environment \& Arid Land Agriculture Sciences, Vol. 22, No.1, 2011

[6] M. M. Uy, "The status of chemical safety and security in Universities in Mindanao, Philippines", Journal of Chemical Health and Safety, Vol. 18, No. 6, pp. 8-14, 2011

[7] I. Miliszewska, E. M. Sztendur, "Playing it Safe: Approaching Science Safety Awareness through Computer Game-Based Training", Issues in Informing Science and Information Technology, Vol. 8, pp. 37-47, 2011

[8] M Abbas, A. M. Zakaria, M. A. Balkhyour, M. Kashif, "Chemical Safety in Academic Laboratories: An Exploratory Factor Analysis of Safe Work Practices \& Facilities in a University", Journal of Safety Studies, Vol. 2, No. 1, pp. 1-14, 2016

[9] M. Richards-Babb, J. Bishoff, J. S. Carver, K. Fisher, J. RobertsonHonecker, "Keeping it safe: Chemical safety in the high school laboratory", Journal of Chemical Health and Safety, Vol. 17, No. 1, pp. 6-14, 2010

[10] D. Mogopodi, B. Paphane, S. Petros, "Assessment of chemical management practices and safety in junior secondary school laboratories in Gaborone", Journal of Chemical Health and Safety, Vol. 22, No. 5, pp. 17-27, 2015

[11] American Chemical Society, Creating Safety Cultures in Academic Institutions, American Chemical Society, 2012 